\title{
A Course in Computer Networking with a Laboratory on a Minimum Budget, for Engineering Technology
}

\author{
Thomas B. Slack, Dean Lance Smith, Jeffrey Franzone, and Allan Proffitt, \\ The University of Memphis
}

\begin{abstract}
The addition of Computer Network Technology as a course in the Computer Engineering Technology Degree program at The University of Memphis was a success; why is enumerated and discussed. Also discussed is the experience gained from offering this course on a rotating basis from 1999 to 2001.

Index Terms--Engineering Technology, Data Network, Cisco
\end{abstract}

\section{Introduction}

The addition of Computer Network Technology as a course in our Computer Engineering Technology Degree program at The University of Memphis was change recommended by the industrial advisory committee. The intent of the class was to introduce the hardware of computer networks. In the past, the only networking exposure was in connection with configuration of operating systems for servers and workstations. A more systems approach would be desirable, but there was not enough money to set up a networking laboratory for the hands-on part.

In the 1990s, access routers became much cheaper as access to the Internet became more prevalent [1]. As new products have been brought into the low-end router line, there has been a conscious effort by Cisco to have these new products use the same user interface (IOS) as used by the more powerful and more expensive routers [2].

At The University of Memphis, we decided to exploit these small Cisco routers to allow the students hands on laboratory experience. These routers were chosen because the user interface is IOS, yet they could be set up, taken down, and stored as part of each laboratory assignment. The equipment could be purchased with department expense money because the price of the router is just under $\$ 1000$ (the upper limit on expense equipment). The course (CETH 4281 Computer Network Technology) was a success due to many factors, including:

- Popularity of the subject matter

- Allowing a choice of a hardware course or a software course

- Durability and ease of using the hardware

- Allowing both undergraduate and graduate students 


\section{Popularity of the subject matter}

It seems self evident that for a class to be successful it must have subject matter in demand. This demand currently is evident in network technology at both the undergraduate and graduate level. Popularity does not guarantee success, but enables the possibility of success.

The first time that 4281 was offered, the class drew the largest group of students that semester. The only class to draw more students between 1999 and 2001 was a class on web page design, another very popular subject.

There are several positive effects of teaching a popular subject. Students enjoy learning, and are excited by the enabling effects of their study. They tend to study more and are willing to invest more time in their efforts. Students tend to remember more if they are convinced that what they are learning is useful. There is less likelihood of cheating or copying other student's work. And if there is copying, it is of the positive kind where both students improve in a competitive manner. Hands on experience, like that obtained in a laboratory can increase the popularity of a popular subject.

Forazan's popular text, Data Communications and Networking, $2^{\text {nd }}$ Ed [3] was chosen for this course. The presentations and homework problems available on line for this book from the publisher make the teacher's task relatively easy.

III. Allowing a choice of a hardware course or a software course

At about the same time that 4281 was introduced, another course (CETH 4241, Internet Technology) with a software emphasis instead of a hardware emphasis was also introduced. Both courses were placed as an option in the curriculum, so that only one need be taken. Having both courses made them both more popular than they would have been alone. Students like choices.

The classes are being offered in the pattern as described in Table 1. Boxes with content indicate that the class was offered.

Table 1. Schedule of offering, and response to classes

\begin{tabular}{|c|c|c|c|c|c|c|c|c|c|c|}
\hline & 1999 & 2000 & 2000 & 2000 & 2001 & 2001 & 2001 & 2002 & 2002 & 2002 \\
& Fall & Spring & Summer & Fall & Spring & Summer & Fall & Spring & Summer & Fall \\
\hline 4281 & U30 & & & & & & U14 & & & \\
Day & G2 & & & & & & G16 & & & \\
\hline 4241 & & & & U19 & & & & & & Uxx \\
Day & & & & G28 & & & & & & Gxx \\
\hline 4281 & & & U4* & & U9 & & & & Uxx & \\
Night & & & G3 & & G16 & & & & Gxx & \\
\hline 4241 & & & & & & U2 & & U6 & & \\
Night & & & & & & G6 & & G3 & & \\
\hline
\end{tabular}

U- number of undergraduates G- number of graduates

Proceedings of the 2002 American Society for Engineering Education Annual Conference \& Exposition Copyright $\left({ }_{0}\right.$ 2002, American Society for Engineering Education 
The rotation was established during the first year and does not follow the pattern. Note that the Engineering Technology Department at The University of Memphis has an extensive night program, and in order to have enough students in the summer, the class is offered at night. The same order of classes is offered every second year is the same. So far, the classes are filled each semester, except the one marked with an “*”. There was a mix up in registration and many graduates were barred from registering until too late, and the course had been already canceled.

IV. Durability and ease of using the hardware

A significant factor in the success of 4281 has been the durability and ease of using the hardware. No router has failed yet. The routers are made of high impact plastic and structural foam. The routers are supplied with cables that are color coded to match the colors on the surface of the routers. Each cable has a different type of connector, so it is difficult to put cables into the wrong socket [4].

The amount of power consumed by the routers is minimal [4], so the impact on a normal room that is already equipped with computers is also minimal. For a large network, it is necessary to be sure to have enough power strips to support the power connections, one for each router, one (or two) for each PC, and one for each Hub. The equipment is typically connected in a configuration like Figure 1, which may require 14 power connections:

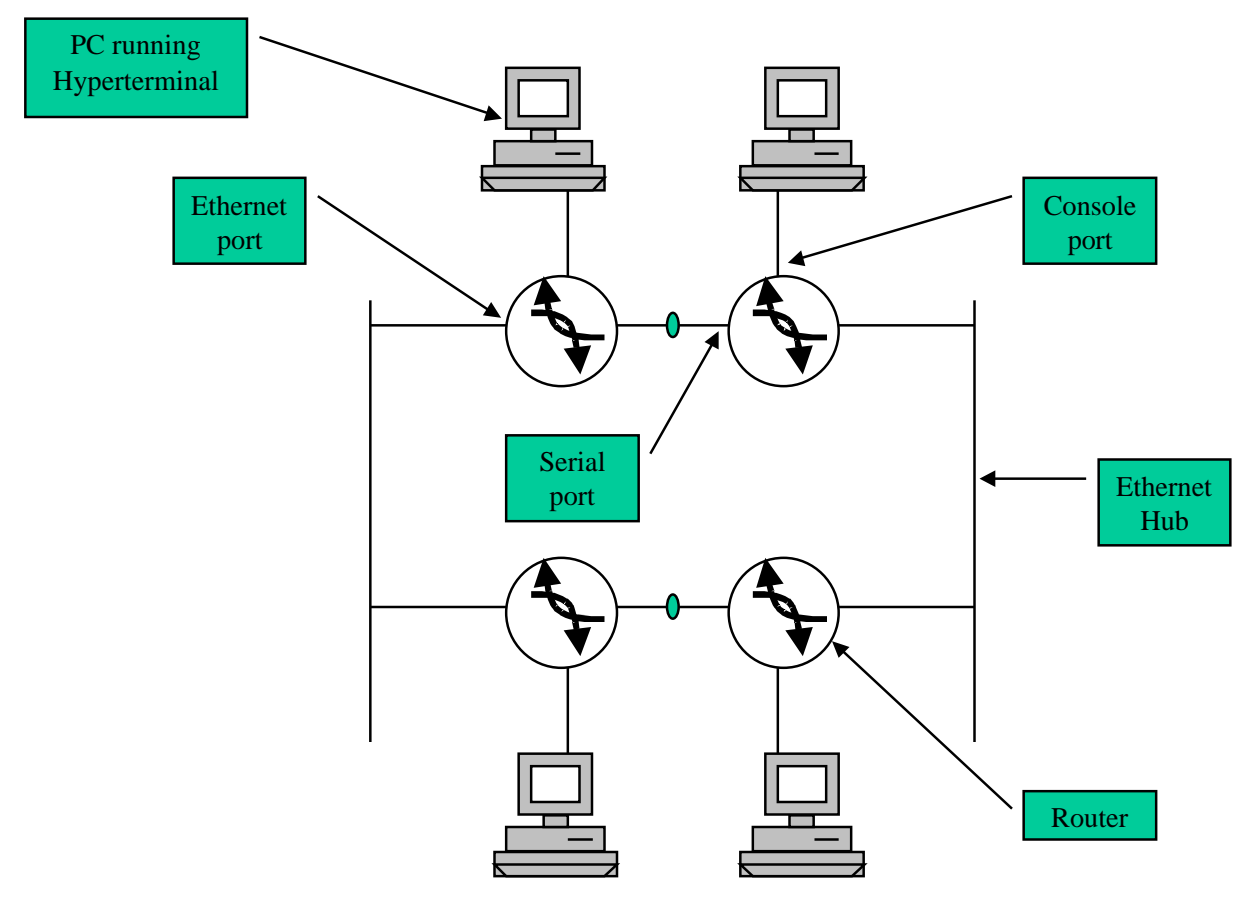

Figure 1. A typical laboratory network

Proceedings of the 2002 American Society for Engineering Education Annual Conference \& Exposition Copyright (C) 2002, American Society for Engineering Education 
V. Allowing both undergraduate and graduate students

One of the most important factors for the success of this and other courses at this level is making the course available to both undergraduate and graduate students. A course must have 12 undergraduates in order to prevent cancellation. Only six graduate students are needed to prevent cancelation. By making the course both graduate and undergraduate, we are able to continue to offer one of the two courses each semester and fill them even though the number of undergraduates is often less than the needed 12.

Often graduate students are interested in both courses although the undergraduates usually choose one or the other to fill the elective. The practical nature of the subject matter lends itself to continuing education while at the same time supporting the undergraduate curriculum.

\section{Summary}

Each of the factors plays an important part in the success of this course. Naturally, since this is an upper division course with obvious application in industry, it is popular with the students. Allowing a choice of different courses actually improves the popularity of each. The durability and ease of use of the hardware makes the maintenance easy. Offering the course to both undergraduate and graduate students allows the course to fill even when the number of seniors would not be enough to offer it without the graduate students. In the future, both CETH 4281 and CETH 4241 could be placed in a new program with a data communications emphasis.

Appendix A. The course laboratories

The first laboratory is simulated using Electronics Workbench. The second uses inexpensive (\$100) breakout boxes for RS/232. The rest of the laboratories use the Cisco routers.

- Laboratory 1: The time domain vs. the frequency domain

- Laboratory 2: RS232 and null modems

- Laboratory 3: Familiarity with IOS

- Laboratory 4: Bridging

- Laboratory 5: Routing

- Laboratory 6: Frame Relay

- Laboratory 7: TFTP, storing configurations on a server

For more information visit The University of Memphis site: http://www.people.memphis.edu/ tslack

\section{References}

[1] "1998 Router Market Share Report" Report Number: WN99-03RT, Cahners In-Stat Group, April 1999, online at: http://www.instat.com/abstracts/WN/1999/WN9903RT_abs.htm

[2] Coulibaly, M. M., "White Paper: Cisco IOS Reference Guide," Cisco Systems Inc. 1999, 54 pages, available online at: http://www.cisco.com/warp/public/620/1.html

[3] Forouzan, B. A., Data Communications and Networking, $2^{\text {nd }}$ Ed. New York: McGraw Hill, 2001. Reference available online at: http://www.mhhe.com/engcs/compsci/forouzan/dcn/

[4] Cisco 805 RouterHardware Installation Guide, Cisco Systems Inc., 1999.

Proceedings of the 2002 American Society for Engineering Education Annual Conference \& Exposition Copyright $\left({ }_{0}\right.$ 2002, American Society for Engineering Education 
THOMAS B. SLACK

Mr. Slack is Assistant Professor of Computer Engineering Technology at the Herff College of Engineering at The University of Memphis. He has 22 years of industrial experience in the areas of computers and network technology. He has his BSE in Electrical Engineering from Arizona State University and his MS in Computer Engineering from Carnegie-Mellon University.

DEAN LANCE SMITH

Dr. Smith is Assistant Professor of Computer Engineering Technology at the Herff College of Engineering at The University of Memphis. He has his BSEE., MSE, and PhD in Electrical Engineering from The University of Michigan-Ann Arbor.

JEFFREY FRANZONE

Mr. Franzone is Assistant Professor of Computer Engineering Technology at the Herff College of Engineering at The University of Memphis. He has his BSE-ET in Electronics Technology, from California State University and his MS in Computer Technology from Arizona State University.

ALLAN PROFFITT

Dr. Proffitt received a Ph.D. in Instrumental Sciences from the University of Arkansas at Little Rock. Prior to accepting an Assistant Professorship in Engineering Technology at the University of Memphis, Dr. Proffitt served as a Senior Research Engineer at the Caterpillar Center for Manufacturing Excellence. Dr. Proffitt has also taught Engineering at Arkansas Tech University and worked for four years at Lockheed Aerospace.

Proceedings of the 2002 American Society for Engineering Education Annual Conference \& Exposition Copyright $\left({ }_{0}\right.$ 2002, American Society for Engineering Education 